\title{
INTEGRAÇÃO DA REDE DE PROTEÇÃO À MULHER EM SITUAÇÃO DE VIOLÊNCIA DOMÉSTICA E FAMILIAR NAS MEDIDAS PROTETIVAS DE URGÊNCIA
}

\author{
Marcela Santana Lobo* \\ Adriana Ramos de Mello*
}

\section{RESUMO}

O pleno acesso à justiça de mulheres em situação de violência constitui direito fundamental reconhecido em compromissos internacionais dos quais o Brasil é signatário, na Constituição Federal de 1988 e na Lei Federal 11.340/2006, podendo tal garantia ser compreendida pelos atos realizados nos processos judiciais para atuação da rede de atendimento à mulher. Por meio do estudo de casos que refletem procedimentos adotados em medidas protetivas, refletese nesse artigo sobre como marcadores, a exemplo de raça e classe social, estão assinalados e sobre a relevância do aprimoramento de atuação em rede na prevenção do ciclo de violência.

Palavras-chaves: Direitos fundamentais das mulheres; Acesso à Justiça; Violência doméstica; Interseccionalidade; Medidas protetivas de urgência.

\section{INTEGRATION OF THE PROTECTION NETWORK TO WOMEN IN A SITUATION OF DOMESTIC AND FAMILY VIOLENCE UNDER THE PROTECTIVE MESURES OF URGENCY}

\begin{abstract}
The full access to justice for women in situations of violence is a fundamental right recognized in international commitments in which Brazil is signatory, in the Federal Constitution of 1988 and in the Federal Law 11.340/2006, being this guarantee understood by the acts in the judicial processes for performance of the women's service network. Through the case studies the reflect procedures adopted in the judgment of protect measures, this article reflects on how markers such as race and social class are highlighted and about the relevance of improving network performance in the prevention of the cycle of violence against women.
\end{abstract}

Keywords: Fundamental women rights; Access to justice; Domestic Violence; Intersectionality; Urgent protect measures.

\section{INTRODUÇÃO}

\footnotetext{
* Juíza de direito. Aluna do Mestrado Profissional em Direito e Poder Judiciário da ENFAM - Escola Nacional de Formação e Aperfeiçoamento dos Magistrados. E-mail: marcelalobo@gmail.com

* Juíza de direito. Doutora em Direito Público e Filosofia jurídico-política pela Universidade Autônoma de Barcelona. Professora da EMERJ e do Mestrado Profissional da ENFAM - Escola Nacional de Formação e Aperfeiçoamento dos Magistrados. E-mail: mello.adriana25@gmail.com
} 
Dados apresentados pelo Altas da violência de 2020 apontam que "entre os anos de 2008 a 2018, o Brasil teve um aumento de 4,2\% nos assassinatos de mulheres" (IPEA, 2020, p. 35). Em 2018, uma mulher foi assassinada no Brasil, a cada duas horas, totalizando 4.519 vítimas. Naquele ano, 68\% das mulheres assassinadas no Brasil eram negras (IPEA, 2020, p. 37). É necessário, portanto, que a violência contra as mulheres seja compreendida, sob o enfoque interseccional, demandando soluções sistêmicas.

Não restrito às fronteiras brasileiras, o enfrentamento à violência contra a mulher é um desafio global que conclama a adoção de políticas públicas ajustadas e coerentes com a missão de identificá-la, preveni-la e oferecer resposta às demandas surgidas. Ademais, representa grave violação de direitos humanos, constitui problema de saúde pública, e seus impactos afetam direta e indiretamente uma coletividade de relações sociais. Por tais razões, a igualdade de gênero foi incorporada como objetivo de desenvolvimento sustentável na Agenda 2030, figurando como uma das metas (5.2) eliminar todas as formas de violência contra todas as mulheres e meninas nas esferas públicas e privadas (PLATAFORMA AGENDA, 2030).

As situações de violência, consideradas atos intencionais, merecem, inclusive, a conceituação de epidemia silenciosa. Destacam-se, entre elas, a violência de gênero cuja compreensão se reconhece transversal a conceitos como patriarcado e racismo, segundo Carneiro (2019), Crenshaw (1991) e Saffioti (2015).

Se o documento inaugural para proteção jurídica das mulheres assentou-se nas bases da promoção de igualdade de gênero, a disciplina posterior dos direitos humanos das mulheres avançou para incluir temas afetos especificamente à violência, estabelecendo conceitos que orientaram a produção legislativa. No Brasil, a Lei Federal no 11340/2006 estabelece as bases da prevenção e enfrentamento à violência doméstica e familiar contra a mulher, reafirmando, em seu artigo $8^{\circ}$, que "A política pública que visa coibir a violência doméstica e familiar contra a mulher far-se-á por meio de um conjunto articulado de ações da União, dos Estados, do Distrito Federal e dos Municípios e de ações não governamentais” (BRASIL, 2006).

O aprimoramento da atuação em rede com os diversos setores do poder público e privado para o enfrentamento à violência é um dos vetores aptos a estimular uma perspectiva que enalteça a mulher, como destinatária da atenção e cuidado, cuja voz possa ser fortalecida no encontro de diversos atores. Como pontuam Schraiber e D’oliveira (1999), a violência é 
uma situação complexa, que demanda o oferecimento de uma escuta responsável à mulher, considerando-a como "um sujeito pleno", não a violentando mais uma vez ao tratá-la como incapaz.

O presente artigo lança algumas luzes sobre a efetivação do acesso à justiça de mulheres em situação de violência, analisando o encadeamento dos atos processuais vinculados aos procedimentos de medida protetiva de urgência, ajuizados em conformidade com a Lei 11.340/2006 e a eventual participação da rede de enfrentamento à violência doméstica e familiar nessa dinâmica, com foco na concretização de uma igualdade material emancipatória das mulheres.

A metodologia aplicada apoiou-se no estudo de caso, com a seleção de procedimentos de medida protetiva de urgência que tramitaram no ano de 2019 na $2^{\text {a }}$ Vara Especial de Violência Doméstica e Familiar de São Luís, no estado do Maranhão, única vara do estado cuja competência é exclusiva para essas demandas. O objetivo será identificar como os indicadores de raça, classe e escolaridade são destacados, e como a rede de enfrentamento à violência é articulada a partir da narrativa trazida pela vítima. Como aporte teórico, apontam-se as reflexões acerca do patriarcado e a interseccionalidade, com foco nas reflexões introduzidas pelo feminismo negro, trazidas por Heleieth Saffioti, Sueli Carneiro e Kimberle Crenshaw.

A seleção dos procedimentos e do objeto de análise foi realizada no primeiro trimestre de 2019, ano antecedente à pandemia do coronavírus causador da COVID-19*, o que permitiu vislumbrar o desenho traçado sem as influências da desarticulação das atividades, inevitável no contexto de calamidade publicamente declarado, decorrente da pandemia Covid19. A pesquisa pretende examinar as convergências e diferenças procedimentais e de encaminhamento adotadas no curso do ano do ano de 2019, iniciando pelo destaque de três casos selecionados. Examina-se como estão documentadas as questões de raça e classe em tais procedimentos, como indicadores relevantes na violência de gênero (FÓRUM, 2020; PCSVDF $\left.F^{\text {Mulher }}, 2017\right)$, e que encaminhamentos são realizados a partir da primeira provocação ao Poder Judiciário.

\footnotetext{
* Em 11 de março de 2020 a Organização Mundial de Saúde reconheceu a pandemia do coronavírus causador da COVID-19. No Brasil, a declaração de calamidade pública ocorreu em 20 de março daquele ano, afetando diretamente o funcionamento de diversos serviços públicos. Em 05 de abril de 2021, o Brasil conta com mais de 13 milhões de casos e mais de 332 mil óbitos em decorrência do COVID-19. Dados coletados no painel CONASS, disponível em: <https://www.conass.org.br/painelconasscovid19/>.
} 


\section{DO ACESSO QUALIFICADO À JUSTIÇA PARA MULHER EM SITUAÇÃO DE VIOLÊNCIA DE GÊNERO COMO DIREITO HUMANO FUNDAMENTAL}

A convenção sobre a eliminação de todas as formas de discriminação contra a mulher, de 1979, doravante chamada CEDAW, foi o primeiro documento internacional a tratar de forma ampla sobre os direitos humanos das mulheres, com a instituição de duas frentes principais: promover esses direitos na busca da igualdade de gênero e reprimir quaisquer discriminações contra as mulheres nos Estados-partes (BRASIL, 2002). Para Pimentel (2020), esse documento deve ser considerado um parâmetro mínimo na promoção dos direitos humanos das mulheres e na repressão às suas violações, nos âmbitos público e privado.

Tornando a igualdade um objetivo, a convenção estabelece medidas legais, políticas e programáticas a serem adotadas pelos Estados-partes na implementação de diretrizes tendentes à eliminação da discriminação contra a mulher. Piovesan (2012) destaca que o sistema geral realçado naquele documento é endereçado a toda e qualquer pessoa, enquanto o sistema especial de proteção destaca o sujeito de direito, visto em sua especificidade e concreticidade.

Baer (2016) sugere que a igualdade seja considerada um vértice de um triângulo, no qual também figurem dignidade e liberdade, perfazendo assim preocupações fundamentais reconhecidas no direito. A autodeterminação deve ser protegida, contrapondo-se a um paternalismo igualitário; o direito deve ser compreendido como ele é, não como um costume, mas em uma perspectiva de dignidade; e, por fim, deve ser assegurado que todos possam usufruí-lo, reconhecendo a diversidade de seres humanos.

Nessa linha, Crenshaw (1991) argumenta que, no contexto de violência contra a mulher, o apagamento das diferentes identidades pode se tornar problemático, especialmente porque a violência que muitas mulheres experimentam pode ser talhada por outras dimensões de suas identidades, como raça e classe. O encontro entre igualdade, dignidade e liberdade deve considerar as especificidades vinculadas ao acesso ao Poder Público, que atravessam questões fundantes como gênero, raça e classe (CARNEIRO, 2019; SAFFIOTI, 2015).

A Recomendação Geral no 33 da CEDAW aprofunda o debate acerca da proteção à mulher, discorre sobre o direito de acesso à justiça para as mulheres e assinala que "o efetivo acesso à justiça otimiza o potencial emancipatório e transformador do direito" (ONU, 2015, p. 3). Pontua, ainda, que a maioria das constituições nacionais apresenta garantias relativas à 
igualdade sexo ou gênero perante lei. Esse é o caso da norma fundamental brasileira, que enuncia o princípio da igualdade entre homens e mulheres no caput de seu artigo $5^{\circ}$ e no inciso I (BRASIL, 1988). Embora contemple a igualdade formal, muitos são os obstáculos impostos às mulheres no Brasil para alcançar igualdade real quando comparadas aos homens.

\begin{abstract}
A discriminação contra as mulheres, baseada em estereótipos de gênero, estigmas, normas culturais nocivas e patriarcais, e a violência baseada no gênero, que particularmente afeta as mulheres, têm um impacto adverso sobre a capacidade das mulheres para obter acesso à justiça em base de igualdade com os homens (ONU, 2015, p. 4).
\end{abstract}

A Recomendação Geral no 33 (ONU, 2015, p. 6) destaca, entre os fatores impeditivos do acesso das mulheres à justiça: a) concentração de tribunais e órgãos quase judiciais nas principais cidades e sua não disponibilidade em regiões rurais e remotas; b) o tempo e o dinheiro gastos para acessá-los; c) a complexidade dos procedimentos; d) barreiras físicas para as mulheres com deficiências; e) a falta de acesso à orientação jurídica de alta qualidade e competente em matéria de gênero, incluindo a assistência jurídica; f) as deficiências na qualidade dos sistemas de justiça, por exemplo as decisões ou julgamentos insensíveis a gênero, devido à falta de formação, à demora e à duração excessiva dos procedimentos, à corrupção.

Quando se reflete sobre o acesso à justiça de mulheres em situação de violência de gênero, há de se observar a efetivação de direitos fundamentais que garantem efetiva igualdade, em especial a superação de obstáculos materiais e o acesso à orientação jurídica de qualidade, com garantia de assistência jurídica no curso dos processos. Não é suficiente, portanto, o mero acesso formal a profissionais da área jurídica. É fundamental que eles sejam capacitados para atuar de forma sensível ao gênero e que as regras processuais sejam revisadas a fim de assegurar igualdade entre as partes, conforme descrevem os itens 15.b e 15.g da Recomendação no 33 (ONU, 2015, p. 7). A seção E, item 36 da Recomendação Geral $n^{\circ} 33$ da CEDAW (ONU, 2015, p. 16) trata taxativamente da relevância da assistência jurídica e da defensoria pública para atuação da defesa da mulher, assinalando ser um elemento crucial na garantia dos direitos humanos das mulheres a "prestação de assistência, aconselhamento e representação jurídica gratuita ou a baixo custo nos processos judiciais ou quase judiciais em todos os campos do direito". 
Estabelecidos os fundamentos para erigir a igualdade material como objetivo a nortear a atuação do sistema de justiça e avançando na sinalização da violência contra a mulher como violação dos direitos humanos e liberdades fundamentais, tem-se a Convenção Belém do Pará como documento central (BRASIL, 1996). A violência contra a mulher pode ser física, sexual e psicológica, perpetrada ou tolerada, inclusive, pelo Estado ou seus agentes, onde quer que ocorra (art. 2, letra c).

[A Convenção Belém do Pará] é o primeiro tratado internacional de proteção dos direitos humanos a reconhecer, de forma enfática, a violência contra as mulheres como um fenômeno generalizado, que alcança, sem distinção de raça, classe, religião, idade ou qualquer outra condição, um elevado número de mulheres (PIOVESAN, 2014, p. 8).

Percebe-se com clareza que o desenho para reconhecimento de direitos humanos das mulheres contempla o acesso qualificado à justiça como peça fundamental para a emancipação e o desenvolvimento femininos, devendo o Estado comprometer-se de forma efetiva, e não meramente normativa, com a igualdade dentro do processo, a proteção da mulher nos sistemas de justiça e a consolidação da relevância de uma atuação com perspectiva de gênero nos procedimentos extrajudiciais e judiciais. Ao ratificar documentos de proteção à mulher, o Brasil assumiu compromissos para garantia de direitos, devendo, para tanto, observar as obrigações, planos, metas e estratégias implementadas.

\begin{abstract}
Além do fato de que muito em termos de ações, planos e metas deve ser implementados, no que tange à realização dos direitos declarados na Convenção, uma especial preocupação é dirigida aos atores jurídicos: poucos são os que conhecem e principalmente aplicam os documentos internacionais dos quais o Brasil é signatário. No que se refere à Convenção Belém do Pará, o prejuízo é bastante acentuado, exatamente por ela representar um avanço de fundamental importância na reconceituação dos direitos das mulheres à não violência. Ele é, atualmente, ao lado da Lei Maria da Penha, o principal instrumento a tratar da matéria (BIANCHINNI, 2016, p. 124)
\end{abstract}

No âmbito interno, a Constituição Federal de 1988, em seu artigo 226, §8º, institui ser dever do Estado criar mecanismos para coibir a violência no âmbito das relações familiares (BRASIL, 1988). Não obstante a previsão constitucional, o Brasil, na Comissão Interamericana, fora condenado por negligência e omissão em relação à violência doméstica (CIDH, 2001). Um dado interessante, contemporâneo à análise da situação brasileira pela corte internacional e destacado por Saffioti (2015, p. 66) é a inviabilização da violência 
doméstica a partir das dinâmicas processuais introduzidas pela Lei 9.099/95, que terminou por "legalizar pelo menos a violência doméstica". É que, por aqueles institutos legais, ficava autorizada a concessão de transação penal e composição civil aos crimes praticados em um contexto de violência doméstica, afastando, em muitos casos, a mulher do acesso a outra autoridade que não fosse a policial. A mulher continuava desassistida juridicamente e a violência por ela sofrida era rotulada como de "menor potencial ofensivo".

Em 2006 adveio a Lei Federal 11.340, que criou mecanismos para coibir a violência doméstica e familiar contra a mulher, dispôs sobre a criação dos juizados de violência doméstica e familiar contra a mulher e promoveu alterações em leis do sistema penal, processual penal e de execução da pena. Em seu artigo $3^{\circ}$, preceitua o imperativo de assegurar às mulheres as condições para o exercício efetivo de seus direitos fundamentais, bem como determina que o poder público desenvolva políticas para resguardar as mulheres, no âmbito das relações domésticas e familiares, "de toda forma de negligência, discriminação, exploração, violência, crueldade e opressão. Entre as medidas integradas de prevenção à violência (art. $8^{\circ}$ ), institui a integração operacional e a "adoção de uma perspectiva de gênero e de raça ou etnia, concernentes às causas, às consequências e à frequência da violência doméstica e familiar contra a mulher" (BRASIL, 2006).

O acesso qualificado ao Poder Público é um reflexo do avanço civilizatório e demanda que a atenção a grupo sociais minorizados se exteriorize no reconhecimento dos marcadores adequados à compreensão dos fenômenos sociais. No caso da violência contra a mulher, podem ser apontados como marcadores essenciais a raça e a classe/renda. No contexto de relações multirraciais, pluriculturais e racistas, há que se reconhecer o impacto do racismo sobre as relações de gênero, uma vez que, "ele determina a própria hierarquia de gênero em nossas sociedades" (CARNEIRO, 2019, p. 315). Entretanto, como destaca a autora, "o mito da democracia racial presente em todas nós torna desnecessário o registro da cor” (p. 314). Talvez, por essa razão, careça o destaque à raça de mulheres e homens apontados como partes no âmbito de procedimentos em trâmite no poder Judiciário.

Apenas em 2020, o formulário de avaliação de risco foi introduzido no âmbito do Poder Judiciário e do Ministério Público, com a sugestão de sua implementação no âmbito das Polícias Civis, quando do registro da ocorrência policial (CNJ, 2020) ${ }^{\dagger}$. Dotado desse

\footnotetext{
${ }^{\dagger}$ Em 5 de dezembro de 2018 foi assinado Termo de Cooperação Técnica entre o Conselho Nacional de Justiça, o Conselho Nacional do Ministério Público e Ministério de Direitos Humanos, para criação e implementação do
} 
instrumental é possível adotar procedimentos sistematizados para identificar fatores que possam sinalizar a possibilidade de novas violências e a potencial letalidade (MEDEIROS, 2015).

Outro ponto a merecer destaque é a efetivação do direito à assistência judiciária no curso dos procedimentos, reconhecido nos artigos 9, 27 e 28 da Lei Federal 11. 340/2006, como garantia à mulher em situação de violência. Nos exatos termos do artigo 27: "Em todos os atos processuais, cíveis e criminais, a mulher em situação de violência doméstica e familiar deverá estar acompanhada de advogado, ressalvado o previsto no art. 19 desta Lei” (BRASIL, 2006).

O artigo 19 mencionado trata do instituto da medida protetiva de urgência e da concessão de capacidade postulatória à mulher para requerê-la, instituindo um acesso amplo e irrestrito para o conhecimento de situações que demandem a intervenção imediata do Estado para fazer cessar a violência. A medida protetiva de urgência é um instrumento inovador a serviço das mulheres e que revoluciona mecanismos de proteção.

A descrição sucinta do procedimento inicial está no artigo 18 (BRASIL, 2006), que determina, uma vez recebido o expediente com o pedido da ofendida, que o juiz o conheça no prazo de 48 (quarenta e oito) horas e decida sobre as medidas a serem tomadas. Nesse mesmo prazo, deverá encaminhar a ofendida ao órgão de assistência judiciária, quando for o caso, comunicar ao Ministério Público, para que adote as providências cabíveis e determine a apreensão imediata de arma de fogo sob a posse do agressor (incisos I, II, III e IV).

Por disposição legal, portanto, desde o momento em que é apresentada a medida protetiva, se a mulher não estiver representada por um defensor, deverá ser encaminhada ao órgão de assistência judiciária, a fim de que seja acompanhada e orientada no curso do processo (medidas ou ação penal). Essa recomendação também é replicada na Resolução ${ }^{\circ}$ 253 do Conselho Nacional de Justiça, ao indicar como parte da política institucional do Poder Judiciário de atenção e apoio às vítimas de crimes e atos infracionais o encaminhamento para "rede de serviços públicos, incluídos os serviços de assistência judiciária, assistência médica, psicológica e social disponíveis na localidade" (CNJ, 2018a).

Entretanto, carências estruturais da Defensoria Pública no Brasil, ausência de leitura sistêmica da legislação e falta de capacitação em atuação na perspectiva de gênero

Formulário Nacional de Avaliação de Risco. Em janeiro de 2019, foi constituído Grupo de Trabalho, cujas conclusões foram apresentadas em maio de 2019. Após, o modelo sugerido foi aprimorado, com a instituição da versão cuja utilização se recomendou em 2020. 
comprometem a efetivação desse direito, fazendo com que a proteção efetiva à mulher seja enfraquecida no curso do processo. Em comentários ao artigo 27 da Lei 11.340/2006, Sanches e Pinto (2021, p. 307) apontam:

\begin{abstract}
Interessante que o dispositivo obriga a presença de advogado, no acompanhamento da vítima, inclusive para as audiências criminais. Assim, a título de exemplo, enquanto o art. 68 da lei 9099/1995 (Lei dos Juizados Especiais Criminais) impõe a obrigatoriedade de um defensor (constituído ou dativo) em prol do autor do fato, a presente lei vai além, exigindo que também a ofendida esteja, em todos os atos do processo, assistida por advogado, sem prejuízo da presença do Ministério Público que é também obrigatória. A ratio legis foi a de garantir maior proteção à ofendida, uma preocupação que também se manifesta no art. 16 da lei, ao determinar que eventual renúncia ao direito de representação seja expressada na presença do juiz, do membro do Ministério Público e, por força do dispositivo em estudo, também do advogado.
\end{abstract}

Percebe-se, assim, que, assegura-se legalmente a igualdade entre homem e mulher para dispor da mesma atenção e orientação, entretanto, em termos práticos e em regra, apenas réu, homem na maioria dos casos, permanece acompanhado de defensor no curso das ações penais, privando-se a mulher de efetiva participação e do exercício de uma influência qualificada nos processos decisórios. Como pontua Barsted (2012, p. 108), a Lei 11.340/2006 definiu linhas de uma política nacional de prevenção e atenção no enfrentamento da violência contra a mulher, reforçando, entre outras medidas, a atuação da Defensoria Pública na assistência jurídica. Tal atuação é fundamental para a efetivação da igualdade processual, permitindo que a mulher expresse suas posições, ampliando a sua proteção. E, prossegue a autora recordando que, a legislação espanhola deu "ênfase aos mecanismos de proteção às mulheres em risco social", criando "uma ampla rede de apoio capaz de diminuir os atos índices de violência contra as mulheres e responder às suas necessidades, que vão além da esfera criminal" (op cit). Comentando os desafios e novos paradigmas para defesa da mulher em situação de violência, Mello e Paiva (2020, p. 302) pontuam que:

A presença da assistência jurídica à mulher é muito importante nas audiências, sejam especiais, sejam de instrução e julgamento. As mulheres em situação de violência doméstica frequentemente se encontram abaladas emocionalmente, e possuem dúvidas acerca dos procedimentos judiciais. Portanto, é fundamental que a defesa, seja ela realizada pela defensoria ou por advogados particulares, trabalhe sempre levando em consideração os sentimentos e autonomia das mulheres. 
No sumário executivo "O poder judiciário no enfrentamento à violência doméstica e familiar contra as mulheres" (2019), IPEA e CNJ fizeram achados que merecem destaques. Sobre a dinâmica das audiências, descreve o estudo que:

\begin{abstract}
Independentemente de haver ou não proferimento de sentença durante as audiências, as mulheres, em geral, saem das unidades sem saber o desfecho dos seus casos. Como normalmente são as primeiras a serem escutadas, são liberadas logo após a tomada de seu depoimento e acabam deixando as unidades. Registre-se ainda que, nas situações em que permanecem na sala de audiência, elas tampouco são informadas de como ficarão sabendo o que vier a ser decidido no caso. E se tiverem dúvidas, não será ali que terão a possibilidade de vê-las esclarecidas. Qualquer subversão à fluidez da audiência é afastada pelo juiz (CNJ, 2019, p. 11)
\end{abstract}

Em relação ao acolhimento e procedimentos de cuidado, esclarece o documento:

Outro aspecto observado durante as audiências foi insuficiência ou inexistência de assistência jurídica para as mulheres, embora o artigo 28 da Lei Maria da Penha lhes garanta o acesso a este serviço, prestado pela Defensoria Pública ou por outro meio gratuito. Apenas algumas localidades contam com núcleos da Defensoria especializados em VDFM; esta diferença fica destacada, sobretudo, entre as unidades do interior e as de capital ou região metropolitana. De maneira geral, os poucos defensores vistos em atuação nos casos de competência da LMP estão designados para defender quem está sendo processado.

Esta situação é coerente com a percepção corrente entre os atores jurídicos sobre o papel da mulher nos processos de VDFM. Um juiz expressa nitidamente a questão: "ela está ali como informante, ela não é testemunha, ela é informante". Ou seja: como a autoria da denúncia é do MP, as mulheres não são parte nos processos e participam somente para contribuir na instrução; por outro lado, o MP, como "fiscal da lei”, já estaria atuando pela vítima. Daí a pouca importância conferida à disponibilização de assistência jurídica para as mulheres em situação de violência.

(...)

Durante as audiências e os atendimentos às mulheres, notou-se ausência de preocupação também com o esclarecimento e a orientação adequada às mulheres. Embora haja esforços para prestar informações suficientes e compreensíveis, o uso indiscriminado de termos jurídicos e/ou técnicos e excessivamente formais é um obstáculo indisfarçável, que compromete a compreensão e a participação das mulheres no processo (CNJ, 2019, p. 13, grifos do original)

Prevalecendo a visão tradicional do processo criminal, há persistente alijamento da mulher que vivencia situação de violência, ouvida, em muitos casos, de forma fragmentada e sem a construção de uma participação integral no processo. A ausência de enunciação e compreensão das etapas processuais e de seus objetivos também compromete a qualidade dos serviços prestados e evidencia a vulnerabilidade da mulher quando inserida nos sistemas judiciais. Torna-se a mulher um simples objeto da prestação jurisdicional, e não a titular de direitos cuja proteção se pretende. Ademais, é possível que perspectiva emancipatória fique 
invisibilizada quando a atuação em rede é comprometida, obscurecendo aspectos relevantes da narrativa da violência sofrida e diluindo a importância de outros atores.

Ensina Campos (2012), inspirada nas lições de Katherine Barlett, ser fundamental formular a questão da mulher ou "onde estão as mulheres? tendo como objetivo "iluminar as implicações de gênero de uma prática social ou de uma norma jurídica”. Deve-se, assim, questionar-se como "as mulheres têm sido (des) consideradas pela lei" e como eventual omissão pode ser corrigida. Refletindo sobre a etapa de requerimento e processamento das medidas protetivas, verifica-se que a ausência de alinhamento inviabiliza, em muitos momentos, o pleno acesso da requerente aos serviços que lhe poderiam ser ofertados. Em que momento ela é esclarecida dos serviços que lhe são disponibilizados e sensibilizada sobre como isso pode cooperar no rompimento do ciclo da violência são questões relevantes que podem ser investigadas.

Sem dúvida, a construção dos procedimentos judiciais se ampara em tradições patriarcais e no exercício do poder dele decorrente. Ainda que se considere a relevância da imposição de medidas cautelares de proteção e de sanções penais adequadas, não se pode olvidar que a complexidade do fenômeno da violência de gênero demanda respostas criativas e uma atuação dinâmica, com atribuição de olhares diversos e aprofundados.

Urge, assim, repensar a posição da mulher dentro dos procedimentos, cautelares ou ordinários, garantindo a sua regular e qualificada proteção, sem o exercício de um paternalismo institucional, atrelado ao próprio reconhecimento do patriarcado, e que, segundo Saffioti (2015, p. 60) "configura um tipo hierárquico de relação, que invade todos os espaços da sociedade". É fundamental que a mulher seja orientada e acompanhada, de forma a compreender as etapas e processos vinculados, destacando a sua importância na construção de soluções a considerar a recorrência das situações de violência e influência das questões sociais e culturais.

Importa, igualmente, considerar fatores, como raça e desigualdades econômicas e educacionais, como impactantes no acesso à justiça, a afetar a compreensão das questões processuais, o entendimento sobre a relevância de assistência jurídica qualificada impactando na qualidade da tomada de decisões. O "analfabetismo jurídico" pode se tornar um aprisionador em situações de violência. Assim, o marcador racial deve estar corretamente identificado, despertando o alerta institucional, haja vista serem as mulheres negras mais afetadas como vítimas de feminicídios, têm maiores dificuldades de acesso ao mercado, 
recebem menores salários e são mais atingidas com mais intensidades por outras violências, inclusive institucionais. Como assevera Crenshaw (2002, p. 177),

\begin{abstract}
Intervenções baseadas em compreensões parciais e por vezes distorcidas das condições das mulheres são, muito provavelmente, ineficientes e talvez até contraproducentes. Somente através de um exame mais detalhado das dinâmicas variáveis que formam a subordinação de mulheres racialmente marcadas pode-se desenvolver intervenções e proteções mais eficazes.
\end{abstract}

Há uma correlação entre a privação a serviços básicos e à dignidade que se perpetua na insuficiência de orientação jurídica, no apagamento da mulher vítima no curso do processo, na impossibilidade de arcar financeiramente com uma assistência adequada e na ausência de continuidade de oferecimento da atenção em rede, o que pode contribuir, na presença isolada ou cumulativa desses fatores, em perpetuação dos ciclos de violência.

\title{
3 METODOLOGIA
}

Trata-se de uma pesquisa qualitativa, de caráter analítico, que utiliza como técnica o estudo de caso, sobre a qual Chizzotti (1995, p. 102), explica que "é a pesquisa para coleta e registro de dados de um ou vários casos, para organizar um relatório ordenado e crítico ou avaliar analiticamente a experiência com o objetivo de tomar decisões ou propor ação transformadora". Monteiro e Savedra (2001) consideram a técnica como relevante instrumento para o campo jurídico, na medida em que os resultados dos estudos de caso servem de base para outras pesquisas.

Para a investigação da atuação em rede na proteção da mulher em situação de violência doméstica, elegeu-se o ano de 2019 para a coleta de dados, fundamentalmente por ter sido o ano antecedente à pandemia de COVID-19, evento que impactou na continuidade dos serviços prestados, agregando, ainda, outros elementos à violência em decorrência do isolamento, desemprego e desagregação dos serviços públicos.

A vara escolhida como campo de pesquisa será a $2^{\text {a }}$ Vara Especial de Violência Doméstica e Familiar da comarca de São Luís, no estado do Maranhão, única desse estado a possuir como competência exclusiva o processamento e julgamento de medidas protetivas de 
urgência. Foram selecionados três procedimentos, todos distribuídos no primeiro semestre de $2019^{*}$.

Como premissa é importante registrar que não há descrição legal para o procedimento das medidas protetivas de urgência. Interessava, assim, compreender como os atores se interconectavam no curso do rito e que aspectos foram realçados nas narrativas trazidas aos autos.

\section{RESULTADOS E DISCUSSÃO}

A Mulher 1 registrou ocorrência na Delegacia Especializada. Informou, na ocasião, que manteve um relacionamento conjugal por dois meses, estando separada há aproximadamente dois meses. O motivo do rompimento seria o comportamento possessivo do ex-companheiro. Inconformado com a separação, o requerido passara a ameaçar sua excompanheira. Invadiu a residência da declarante, quebrou uma janela e a agrediu com um pedaço de madeira na mão e pernas, causando lesões. Nessa ocasião teria, ainda, ameaçado a irmã da declarante que tentou interceder. O agressor teria saído do local prometendo retornar armado para matar a ex-companheira. Houve encaminhamento para exame de corpo de delito, sem laudo juntado aos autos.

Essa mulher tinha, então, 21 anos, sem profissão declarada. Não lhe foi perguntado sobre raça, escolaridade e renda. Seu ex-companheiro tinha, então, 26 anos, pedreiro, não usava drogas ou pertencia à facção criminosa. Todas as informações foram prestadas pela mulher na ocasião de seu comparecimento à delegacia. Não possuíam filhos comuns ao tempo do registro. Não houve preenchimento do formulário de avaliação de risco.

A medida protetiva foi deferida, determinando a proibição de aproximação do agressor à ofendida, proibição de contato e proibição de frequentação da residência, pelo prazo inicial de 90 dias. Antes do fim do prazo, a mulher compareceu em Juízo solicitando desistência. Estava desacompanhada de advogado ou defensor. Audiência foi designada, ela compareceu, novamente desacompanhada, na presença de Juíza e Promotora, ratificando sua

\footnotetext{
${ }^{\ddagger}$ Os processos examinados tramitaram eletronicamente no sistema PJE, sob segredo de justiça. Houve a disponibilização do acesso aos autos após solicitação formulada ao Juízo da $2^{\mathrm{a}}$ Vara Especial de Violência Doméstica e Familiar de São Luís a quem agradecemos a gentil cooperação. Foi concedido acesso a três procedimentos de medidas protetivas, tombados sob os números 0803750-57.2019.8.10.0001 (caso 1), 0804986-44.2019.8.10.0001 (caso 2) e 0819035-90.2019.8.10.0001 (caso 3).
} 
intenção de desistir e informando que estava grávida. Houve homologação do pedido, revogação das medidas e extinção do processo.

A Mulher 2 registrou ocorrência na Delegacia Especializada. Informou que manteve um relacionamento com o autor do fato em 2015, que terminara em 2016, motivada por uma traição do ex-namorado. Ao longo dos anos, teria havido encontros esporádicos, informando violência sexual em 2017, sem registro de ocorrência. Relatou ser acompanhada por médico psiquiatra e psicólogo, ter sido diagnosticada com transtornos, estar fazendo uso de medicação e ter tentado suicídio em mais de uma ocasião, também sem registro de ocorrência. Em 2018, refere ter sido novamente violentada sexualmente, com registro de ocorrência, e, nessa ocasião, declina ter sofrido violência institucional. Relata um novo estupro em 2019.

Essa mulher tinha, então, 21 anos, estudante. Não lhe foi perguntado sobre raça, escolaridade e renda. Seu ex-namorado tinha, então, 25 anos, agente de segurança pública, com acesso regular à arma de fogo. Foi informado pela declarante que ele seria usuário de drogas. Não possuíam filhos comuns. Não houve preenchimento do formulário de avaliação de risco.

Duas audiências foram designadas, com oitiva separada da mulher e depois do requerido. Houve designação de defensora para acompanhamento da mulher. O requerido compareceu em sua audiência acompanhado de advogado constituído.

Previamente à oitiva da mulher, o Ministério Público manifestou-se nos autos, informando a existência de procedimento para concessão de medidas protetivas ajuizado em data anterior. Posteriormente, juntou laudo de conjunção carnal que informava a inexistência de vestígios. Em decisão, concluiu-se pela ausência de elementos que permitissem a caracterização de violência de gênero. O procedimento foi extinto, e as medidas protetivas não foram concedidas. Não houve interposição de recurso.

A Mulher 3 compareceu para registro na Delegacia Especializada. Informou que conviveu com o requerido por sete anos, tendo dois filhos. Refere a existência de registro de ocorrência e requerimento anterior e concessão de medida protetiva anterior, já expiradas. Relatou ter havido uma discussão com o requerido por telefone, com injúrias proferidas.

Essa mulher tem 29 anos e dois filhos menores de 12 anos com o requerido, um deles com problemas de saúde que demandam atenção integral (tratamento de câncer). Declara ser doméstica e ser negra. Não há dependência econômica e nem disputas sobre direitos 
envolvendo os filhos. Não há profissão declarada do requerido, que teria 44 anos. Houve preenchimento do formulário de avaliação de risco.

Houve designação de audiência onde foram ouvidas a mulher, na primeira, e o homem, na segunda, separadamente. Em seus comparecimentos em Juízo, estavam acompanhados da defensoria pública. Houve manifestação da defesa da mulher pela regulamentação da visita. Em assistência jurídica ao requerido, o defensor próprio requereu a não concessão do pedido. Em despacho, após oitivas, foi determinada a elaboração de estudo pela equipe multidisciplinar e composição sobre a regulamentação. Antes do fim do prazo, a mulher requereu desistência, sem acompanhamento de defensor, que foi homologada.

Como pontos de convergência nas medidas, tem-se que todas iniciaram na Delegacia Especial da Mulher, após comparecimento pessoal das requerentes. Apenas nesse local foi colhido um relato mais detalhado das violências narradas pelas mulheres. Não houve encaminhamento, nesse momento, a nenhum outro ator da rede de proteção, tal como a Defensoria Pública, em que pese a expressa referência a providências que deveriam ser adotadas pela mulher nas hipóteses de promoção da ação penal privada.

Em um dos casos há referência ao encaminhamento para exame pericial, sem a juntada do laudo aos autos. Em apenas um dos casos houve sinalização de encaminhamento da requerente e do requerido para equipe multidisciplinar, para elaboração de relatório. Inferese que a pretensão seria subsidiar uma decisão mais qualificada, a partir da produção de outros elementos. Não há indicativo de eventual investigação sobre as questões subjacentes da violência doméstica.

A análise dos processos indica que os componentes de raça e classe social restaram invisibilizados. Ainda que se possa fazer inferências sobre a classe e renda, a partir das profissões indicadas e/ou do local de residência, isso é insuficiente para alicerçar a conclusão de dependência econômica. Esse elemento seria uma possibilidade de justificativa sobre a ambiguidade das condutas das requerentes que, após um breve período de tramitação, solicitaram a desistência da medida. A dependência afetiva e a condição de único ou principal provedor da família são circunstâncias lembradas quando se investiga a mudança de discurso da mulher no curso das demandas judiciais que atravessam a violência familiar (SAFFIOTI, 2015, p. 92-93).

Invocando as lições de Baer (2016), é preciso ter cuidado para não incorrer em um paternalismo jurídico, restringindo, assim, a liberdade de escolhas da mulher e, dessa forma, 
restringindo a sua dignidade. Contudo, a atenção aos marcadores de violência expostos no discurso apresentado pela vítima pode indicar a necessidade de outras intervenções, convocando-a a refletir sobre a sua própria vulnerabilidade e sua contribuição para a perpetuação das violências.

$\mathrm{O}$ acesso a armas de fogo é ainda, fator de preocupação quando se trata de violência doméstica. O atlas da violência ressalta que "A flexibilização da política de acesso a armas e munição tem uma forte influência no aumento dos índices de crimes violentos letais intencionais" (IPEA, 2020, p. 11). A menção ao potencial uso de armas é sinalizado em dois procedimentos, facilitando em um pela profissão exercida pelo requerido.

Inquestionável, ainda, que a violência cometida por parceiros e ex-parceiros, bem como a violência sexual causam problemas de saúde física, mental, sexual e reprodutiva para as mulheres, com custos sociais e econômicos altos. A mulher que sofre violência morre diretamente, em consequência desses atos (feminicídio), ou indiretamente, sendo a violência por ela sofrida importante causa para o surgimento de doenças mentais, abuso de álcool e drogas, podendo ser identificada como fator de risco (OPAS, 2005; GARCIA-MORENO; WATTS, 2011). Assim, é de se ponderar a participação de outros atores da rede de prevenção e enfrentamento à violência quando constatado a existência de fatores de risco.

Não obstante a presença da assistência jurídica em dois dos três processos, há uma limitação de suas intervenções. Nas duas situações de desistência, a mulher compareceu sozinha à unidade judicial, manifestando diretamente o seu desinteresse no prosseguimento do feito. Não há informações relativa a atendimentos antecedentes pela Defensoria, a fim de que fossem orientadas quanto às consequências jurídicas de sua decisão. Identifica-se, ainda, uma expansão da função judicial que conta apenas timidamente com a participação de outros atores processuais. A responsabilidade na articulação da rede parece recair com exclusividade sobre o Poder Judiciário.

É relevante, ainda, a compreensão do fenômeno da violência a partir das relações de poder sedimentadas pelo patriarcado, desenvolvidas em relatos de ameaça, agressão e submissão na relação, abuso sexual em situação de vulnerabilidade psicológica e no curso de dependência afetiva e por dinâmica familiar marcadas pela distribuição não equitativa de atividades entre pai e mãe, homem e mulher.

Fundamental, portanto, investigar como a atuação em rede funciona para proteção dos direitos das mulheres em situação de violência, a fim de determinar como vem sendo 
concretizados os compromissos internacionais e constitucionais assumidos pelo Brasil na defesa desse grupo. Relevante, ainda, observar como as interseccionalidades são marcadas dentro de tais procedimentos, com o registro de raça e classe social, bem como se são compreendidos os indicadores vinculados ao potencial agravamento da violência, a fim de que se possa articular um funcionamento com maior fluidez dos atores que participam da rede.

O reconhecimento de que as estruturas da rede não estão organizadas de forma idêntica em todo o território nacional é premissa de qualquer análise. Isto porque a implementação de Juizado Especial de Violência Doméstica ainda é restrita, sendo o conhecimento de matérias vinculadas à violência contra mulheres objeto de análise por juízos criminais privativos ou por varas mistas, na maioria dos casos.

\section{CONSIDERAÇÕES FINAIS}

Para a concretização dos direitos fundamentais enunciados nos tratados e na Legislação Nacional, é urgente e imprescindível para a proteção efetiva da mulher, viabilizar a assistência mínima e eventual superação do ciclo de violência em que se encontra submetida. Os alarmantes números nacionais recomendam a adoção de novas perspectivas processuais, com maior inclusão, acolhimento e participação dos envolvidos, a fim de que a decisão ao final seja incorporada como resultado de medidas cotidianamente tomadas para educação voltada a uma cultura de paz.

O Brasil ratificou as principais convenções que tratam sobre direitos humanos das mulheres, confirmando também em no texto constitucional o compromisso com a construção de uma sociedade livre, justa e solidária, em que a dignidade da pessoa humana seja fundamento e princípio irradiador do sistema, e a discriminação e a violência contra a mulher sejam duramente combatidas na pretensão de sua erradicação. Essa disposição foi reforçada

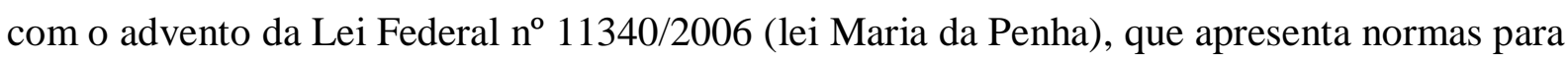
um tratamento diferenciado das situações vinculadas à violência doméstica e familiar contra a mulher, instituindo um sistema articulado para coibir e prevenir.

Passada mais de uma década da edição dessa lei, entretanto, o Brasil continua a lidar com índices alarmantes de violência doméstica. No primeiro semestre de 2020, o número de mulheres assassinadas atingiu 648, representando o aumento de $1,9 \%$ em relação ao mesmo período do ano anterior. Houve queda na notificação de outros delitos, mas a situação de 
calamidade pública em decorrência da pandemia da COVID-19 pode ter influenciado decisivamente no registro de tais ocorrências (IBDFAM, 2020).

A ausência de articulação da rede para atendimento à mulher em situação de violência pode representar, associada a outros a dados, um óbice a efetiva proteção. Isso porque, não obstante a previsão de diversos mecanismos na Constituição, tratados e lei, que inspiram um funcionamento em cadeia e dinâmico dos atores da rede de proteção, na prática o que se vislumbra é um engessamento da atuação, sendo eclipsados elementos fundamentais à compreensão e superação da violência a que está submetida à mulher que busca a atuação estatal.

O fenômeno da violência contra a mulher exige uma atuação multissetorial, bem como permanente capacitação para atuação na perspectiva de gênero, a fim de dotar os sistemas de instrumental, aptos à promoção de uma igualdade real, em que haja a preservação dos direitos de ser ouvida e influenciar nas decisões, acompanhada e orientada por assessoria jurídica qualificada. A gratuidade e o acesso à assistência jurídica são, assim, fundamentais à mulher em situação de violência, notadamente quando se destacam os elementos raciais e de renda associados aos casos documentados ou a ausência deles, evidenciando a persistência do descumprimento de parâmetros fundamentais para a produção de políticas públicas.

Os achados apresentados são ainda preliminares, mas sinalizam a necessidade de uma reflexão sobre o aprimoramento da atuação de diversos atores, a reflexão sobre seus papéis nas relações processuais, a continuidade da formação dos agentes e a quebra dos parâmetros tradicionalistas que se impõem à tramitação dos processos na Justiça. É preciso novas perspectivas que promovam efetivamente a emancipação da mulher e o rompimento dos padrões patriarcais.

\section{REFERÊNCIAS}

BAER, Susanne. Desigualdades que importam. Revista Direito \& Práxis. v. 07, n. 15. Rio de Janeiro: 2016, p. 449-475.

BRASIL. Constituição Federal de 1988. Disponível em:

<http://www.planalto.gov.br/ccivil_03/constituicao/constituicao.htm>. Acesso em $13 \mathrm{dez}$. 2020.

BRASIL. Decreto $\mathbf{n}^{\circ} \mathbf{1 . 9 7 3}$, de $1^{\circ}$ de agosto de 1996. Promulga a convenção interamericana para prevenir, punir e erradicar a violência contra a mulher, concluída em Belém do Pará, em 
9 de junho de 1994. Disponível em: <

http://www.planalto.gov.br/ccivil_03/decreto/1996/d1973.htm>. Acesso em 09 dez 2020.

BRASIL Decreto $n^{\circ}$ 4.377, de 13 de setembro de 2002. Promulga a convenção sobre a eliminação de todas as formas de discriminação contra a mulher, de 1979, e revoga o Decreto no 89.460, de 20 de março de 1984. Disponível em:

<http://www.planalto.gov.br/ccivil_03/decreto/2002/d4377.htm>. Acesso em 10 dez. 2020.

BRASIL. Lei $\mathbf{n}^{0}$ 11.340, de 7 de agosto de 2006. Disponível em: < http://www.planalto.gov.br/ccivil_03/_ato2004-2006/2006/lei/111340.htm>. Acesso em 10 dez. 2020.

CAMPOS, Carmen Hein de. Teoria feminista do direito e a violência íntima contra as mulheres. R. EMERJ. Rio de Janeiro, v. 15, n. 57 (Edição Especial), p. 33-42, jan.-mar. 2012. Disponível em:

<https://www.emerj.tjrj.jus.br/revistaemerj_online/edicoes/revista57/revista57_33.pdf>. Acesso em 11 jan. 21. p. 36

CARNEIRO, Sueli. Enegrecer o feminismo: a situação da mulher negra na América Latina a partir de uma perspectiva de gênero. In: PENSAMENTO FEMINISTA: conceitos fundamentais. Heloisa Buarque de Holanda (Org.). Rio de Janeiro: Bazar do Tempo, 2019.

CHIZZOTTI, Antônio. Pesquisa em ciências humanas e sociais. 2 ed. São Paulo: Cortez, 1995.

CIDH. Comissão interamericana de direitos humanos. Informe n. 54/01, caso 12.051, Maria da Penha Maia Fernandes v. Brasil, de 4 de abril de 2001. Disponível em:

<https://www.cidh.oas.org/annualrep/2000port/12051.htm>. Acesso em $10 \mathrm{dez} 2020$.

CNJ. Conselho Nacional de Justiça. O poder judiciário no enfrentamento à violência doméstica e familiar contra as mulheres. Brasília: CNJ, 2019.

CNJa. Conselho Nacional de Justiça. Resolução no 253 de 04 de setembro de 2018. Disponível em: < https://atos.cnj.jus.br/atos/detalhar/2668>. Acesso em 16 jan. 2021.

CNJ. Conselho Nacional de Justiça. Resolução no 254 de 04 de setembro de 2018. Disponível em: < https://atos.cnj.jus.br/atos/detalhar/2668>. Acesso em 16 jan. 2021.

CNJ. Conselho Nacional de Justiça. Resolução Conjunta no 5 de 03 de março de 2020. Disponível em: < https://atos.cnj.jus.br/atos/detalhar/3218>. Acesso em 02 abr 2021.

CRENSHAW, Kimberle. Documento para o encontro de especialistas em aspectos da discriminação racial relativo gênero. Estudos Feministas, 1/2002. p. 171-188. Disponível em: < https://www.scielo.br/pdf/ref/v10n1/11636.pdf>. Acesso em 06 abr. 2021.

CRENSHAW, Kimberle. Mapping the Margins: intersectionality, identity politics, and violence against women of color. Stanford Law Review. v. 43. July, 1991. p. 1241-1299. Disponível em: < https://www.geledes.org.br/mapeando-as-margens-interseccionalidade- 
politicas-de-identidade-e-violencia-contra-mulheres-nao-brancas-de-kimberlecrenshaw\%E2\%80\%8A-\%E2\%80\%8Aparte-1-4/>. Acesso em 06 abr. 2021.

Fórum Brasileiro de Segurança Pública. Violência doméstica durante a pandemia de COVID-19. Disponível em: <https://forumseguranca.org.br/wp-

content/uploads/2018/05/violencia-domestica-covid-19-v3.pdf>. Acesso em 12 jan 2021

GARCIA-MORENO, Claudia; WATTS, Charlotte. Violence against women: an urgent public health priority. Bulletin of World Health Organ 2011. v. 89, n. 2. Disponível em: < https://www.who.int/bulletin/volumes/89/1/10-085217.pdf?ua=1>. Acesso em 05 abr. 2021.

IBDFAM. Brasil teve 648 casos de feminicídio no primeiro semestre de 2020. Disponível em:

$<$ https://www.ibdfam.org.br/noticias/7853/Brasil+teve+648+casos+de+feminic\%C3\%ADdio +no+primeiro+semestre+de+2020>. Acesso em 12 jan. 2021.

IPEA. Instituto de Pesquisa Econômica Aplicada. Altas da Violência 2020. Disponível em: <https://www.ipea.gov.br/atlasviolencia/download/24/atlas-da-violencia-2020>. Acesso em 05 abr. 2021.

MEDEIROS, Marcela Novais. Avaliação de risco em casos de violência contra a mulher perpetrada por parceiro íntimo. 2015. 235 f. Tese (Doutorado em Psicologia Clínica e Cultura) - Universidade de Brasília, Brasília, 2015.Disponível em:

<https://repositorio.unb.br/handle/10482/20191>. Acesso 05 abr. 2021.

MELlO, Adriana Ramos de; PAIVA, Lívia de Meira Lima. Lei Maria da Penha na prática. 2 ed. São Paulo: Revista dos Tribunais, 2020.

MONTEIRO, Geraldo T.; SAVEDRA, Mônica M. G. Metodologia da pesquisa jurídica. Rio de Janeiro: Renovar, 2001.

ONU. Comitê sobre eliminação da discriminação contra as Mulheres. Recomendação Geral n 33 sobre o acesso das mulheres à justiça de 3 de agosto de 2015. Disponível em: $<$ https://www.tjsp.jus.br/Download/Pdf/Comesp/Convencoes/CedawRecomendacaoGeral33.p df $>$. Acesso em $10 \mathrm{dez} 2020$.

ONU MULHERES. Pesquisa de condições socioeconômicas e violência doméstica e familiar contra a mulher (PCSVDFMulher, Fortaleza, 2017). Disponível em:

$<$ http://www.onumulheres.org.br/wp-

content/uploads/2017/11/violencia_domestica_geracoes_out_17.pdf $>$. Acesso em 12 jan. 2021.

OPAS. Organização Pan-Americana de Saúde. Disponível em: < https://www.paho.org/pt/topics/violence-against-women>. Acesso em 05 abr. 2021.

PIMENTEL, Silvia. Apresentação da convenção sobre a eliminação de todas as formas de discriminação contra a mulher - CEDAW, 1979. Disponível em: 
<http://www.onumulheres.org.br/wp-content/uploads/2013/03/convencao_cedaw.pdf>. Acesso em 10 dez. 2020.

PIOVESAN, Flávia. Temas de direitos humanos. 5 ed. São Paulo: Saraiva, 2012.

PIOVESAN, Flávia. A proteção internacional dos direitos humanos das mulheres. Cadernos Jurídicos, São Paulo, ano 15, n. 38, p. 21-34, Jan.-Abril/2014. Disponível em: $<$ https://core.ac.uk/download/pdf/211912379.pdf〉. Acesso em 10 dez 20. p. 8.

Plataforma Agenda 2030. Disponível em: < http://www.agenda2030.org.br/>. Acesso em 05 abr. 2021.

SAFFIOTI, Heleieth. Gênero, patriarcado e violência. 2 ed. São Paulo: Expressão Popular, 2015.

SANCHES, Rogério Cunha; PINTO, Ronaldo Batista. Violência doméstica: lei maria da penha - Lei 11.340/2006 - comentada artigo por artigo. 10 ed. Salvador: Jus Podivm, 2021.

SCHRAIBER, Lilia B.; D'OLIVEIRA, Ana Flávia Lucas Pires. Violência contra mulheres: interfaces com a Saúde. Interface Botucatu , v. 3, n. 5, p. 13-26, Aug. 1999. Disponível em: <http://www.scielo.br/scielo.php?script=sci_arttext\&pid=S1414-

$32831999000200003 \& \operatorname{lng}=$ en\&nrm=iso >. Acesso em 05 abril de 2021. 